\title{
SINGLE AGENT DOCETAXEL AS SECOND- LINE CHEMOTHERAPY FOR PRETREATED PATIENTS WITH RECURRENT NON- SMALL CELL LUNG CANCER
}

\author{
Deyan N. Davidov, \\ Department of Chemotherapy, Oncological center, \\ Medical University, Pleven, Bulgaria
}

\begin{abstract}
:
Objective: Single agent Docetaxel is a standard therapy for patients with non- small cell lung cancer after the failure of platinum- containing regimens. The aim of this study was to explore the efficacy and safety of Docetaxel monotherapy as second- line chemotherapy in pretreated patient with inoperable non- small cell lung cancer. Methods: From January 2005 to May 2008 thirty- six consecutive patients with locally advanced or metastatic morphologically proven stage IIIB/ IV non- small cell lung cancer entered the study after failure of previous platinum- based regimens. Treatment schedule consist of Docetaxel $75 \mathrm{mg} / \mathrm{m} 2$ administered every three weeks with repetition after 21 days with Dexamethasone premedication. Results: Overall response rate, median time to progression and median survival was $16,6 \%, 4,5$ months and 5,6 months respectively. The main hematological toxicity was neutropenia. Conclusions: That data suggest that single agent Docetaxel remain reasonable choices for the chemotherapy in pretreated patients with non- small cell lung cancer.
\end{abstract}

Key words: Docetaxel, Non- small cell lung cancer, Second- line chemotherapy

\section{INTRODUCTION}

Lung cancer represents a major health problem worldwide. It is the leading cause of cancer- related death in Europe (1), with a 5 - year survival of approximately $15 \%$ for all stages (2). Non- small cell lung cancer (NSCLC) represents approximately $80-\quad 85 \%$ of all lung carcinomas. The vast majority of patients are diagnosed with advanced, unresectable disease (stage IIIB/IV) which remains incurable with a 5-year survival rate of less than 5\% (3). For patients with advanced disease, chemotherapy options are essential for disease control and palliations. Front- line chemotherapy has been substantially improved during the last decade with the introduction of new cytotoxic agents such as gemcitabine, vinorelbine, paclitaxel, docetaxel and pemetrexed; combination of these agents with a platinum compounds represents the standard of care for first- line treatment (4). However, NSCLC patients will inevitably experience tumor progression. Many investigators claim that non- elderly patients with a good performance status (PS) who have relapsed after first- line cisplatin- based chemotherapy require treatment for the relief of tumor- related symptoms and will be suitable for second- line chemotherapy (5). Early reviews of second- line chemotherapy for NSCLC patients reported disappointing results in the treatment of recurrent cisplatinrefractory NSCLC, with response rate (RR) of $<15 \%$ in phase II studies (6).

Docetaxel is semysynthetic taxoid derivate administered as first- line treatment for advanced NSCLC. In several large, prospective, randomized trials Docetaxel has demonstrated activity as salvage treatment in patients with recurrent platinum- refractory NSCLC (7).

The aim of this study was to explore the efficacy and safety of Docetaxel as second- line therapy in pretreated patient with recurrent NSCLC.

\section{PATIENTS AND METHODS}

The eligible patients for this study were treated from January 2005 to May 2008 at Department of Chemotherapy, Oncological center, UMHAT "Dr G. Stranski"- Pleven and they were required to have histological or cytological proof of having stage IIIB or IV NSCLC. All of they had received one prior platinum- containing chemotherapy regimen. Eligibility criteria included age 18- 75 years; World Health Organisation /WHO/ PS of minimum d" 2 ; adequate physiological organ functions: 1) hepatic function (a normal bilirubin level, a normal asparate aminotransferase level and a normal alanine aminotransferase level d"1,5 the upper limit of normal (ULN) and an alkaline phosphatase level d"5 ULN), 2) renal function (a serum creatinine level d"1,5 ULN) and 3) hematological function (an absolute neutrophil count $\mathrm{e}$ " $4 \times 10^{9} / \mathrm{L}$, a platelet count e" $100410^{9} / \mathrm{L}$ and a hemoglobin level $>100 \mathrm{~g} / \mathrm{L}$ ); life expectancy $>12$ weeks; at least one measurable and/or assessable tumor lesion. Measurable disease was assessed either by palpation or radiological assessment ( $\mathrm{x}$ - 
ray, abdominal ultrasound or computed tomography scan).

Patients were excluded if they had a history of severe cardiovascular cardiac disease, hypertension refractory to treatment, symptomatic coronary artery disease, symptomatic brain metastases, presence of active infections, renal or hepatic dysfunction and pregnancy.

Pre- treatment evaluation included a complete medical history and physical examination, laboratory test (hematology and standard biochemistry), chest radiographs, electrocardiogram (ECG). During treatment, a physical examination, an ECG, a blood- cell count with differential, platelet count and standard biochemical assessment (including serum creatinine, urea, sodium, potassium, calcium, transaminases, total bilirubin, total proteins, albumin and lactate dehydrogenase) preceded each cycle. Furthermore, the patient's temperatures, pulse rates and arterial blood pressures were monitored at the beginning and end of Docetaxel administration.

Commercially available Docetaxel was administered at dose $75 \mathrm{mg} / \mathrm{m} 2$ intravenously for one hour on day 1 with 21 day repetition. Treatment was administered until progression or patient's withdrawn. Doses were calculated at the beginning of each treatment cycle and were based on actual body weight. Premedications used to reduce risk of allergic reactions and fluid- retention syndrome consist of Dexamethasone $8 \mathrm{mg}$ given intravenously at $-12,-3,-1,12,24$ and 36 hours after every Docetaxel infusion, and Ranitidine $50 \mathrm{mg}$, Promethazine hydrochloride $50 \mathrm{mg}$ and 5hydroxytryptamine receptor antagonist was given every course and they were administered at the same dosage for each cycle. Docetaxel was discontinued if a patient experienced disease progression, irreversible grade 3/4 toxicity or patient's withdrawal of consent, for a maximum of 6 cycles. Chemotherapy was postponed until attaining recovery of the bone marrow function. The physician determined to continue the consecutive chemotherapy when the patients experienced an objective decline in their performance status.

Patients were evaluated for tumor response every two courses of chemotherapy and every two months after treatment completion. Tumor response was evaluated according to WHO response criteria (8). Response was defined as complete response (CR), partial response (PR), no change (NC), or progressive disease (PD). A CR was defined by the disappearance of all known disease, confirmed by two observations not less than 4 weeks apart. PR was defined as a decrease in tumor size of $50 \%$ or more (either measured or estimated in the case of measurable or assessable disease). In addition, there could be no appearance of any new lesions or progression of any known lesion(s). Objective tumor response included both confirmed $\mathrm{CR}$ and $\mathrm{PR}$. Tumor control rate included $\mathrm{CR}+\mathrm{PR}+\mathrm{NC}$.

The overall survival (OS) duration was defined as the time between the date of starting treatment and the date of the last follow- up or death. Time to progression (TTP) was defined as the time between the date of starting treatment and the date of progressive disease. The response duration was calculated from the day of the observed response until the date of documented progression. The duration of the OS and TTP were estimated using the Kaplan- Meier method and the differences between the Kaplan- Meier curves were evaluated by the log- rank test.

Safety was graded and assessed using the WHO toxicity criteria (9).

\section{RESULTS}

From January 2005 to May 2008 thirty six patients entered the study, including 28 men and 8 women. Some clinical characteristics of these patients are shown in table 1. The median patient's age was 59 (range 39-71). The histopathology most frequently revealed was spinocellulare carcinoma. All patients had previously received chemotherapy as a first- line treatment, and a combination of gemcitabine/ cisplatin was the most common chemotherapy. 14 patients responded to first- line treatment. For 36 patients in this study 12 have chronic disease. Eight had hypertension, three had diabetes mellitus and one pulmonal thrombembolism. The median time from diagnosis of recurrence and initiation of treatment with Docetaxel was 3,3 months. A total of 158 chemotherapy cycles were administered with the median number of cycles/ patients being 4,5.

A response evaluation was assessed for a total of 36 patients. The results achieved are presented on table 2 . The objective response rate was $16,6 \%$ (5 patients). No CR were observed. Six patients $(16,6 \%)$ achieved PR and NC was achieved in 8 patients $(22,2 \%)$. Tumor control rates was observed at 14 patients $(38,8 \%)$. The length of response was a median of 4,5 months. The median OS was 5,6 months for all patients. Out of the 6 patients who had been on a thirdline therapy after docetaxel therapy, one received an EGFR tyrosine kinase inhibitor, and the remaining five were treated with gemcitabine or vinorelbine combination chemotherapy.

Toxicity was quantifiable in all 36 patients and the treatment linked severe toxicities including grade 3 or more neutropenia was observed in 9 patients $(25 \%)$. Grade 3 or more febrile neutropenia occurred in 4 patients $(11,1 \%)$ and anemia grade 3 or more occurred in 2 patients $(5,5 \%)$ too (Table 3). In the cause of grade 3-4 febrile neutropenia broadspectrum antibiotics and granulocyte colony- stimulating factors were administered. No severe /grade 3-4/ thrombocytopenia was observed. The non- hematologic toxicities were generally mild or moderate, and they primarily included peripheral neuropathy- 16 patients $(44,4 \%)$, asthenia8 patients $(22,2 \%)$ and oral mucositis- 11 patients $(30,5 \%)$. Administration of chemotherapy was postponed in 19 cycles. Grade 3- 4 non- hematological toxicity (table 3) include 3 patients $(8,3 \%)$ with diarrhea, 4 patients $(11,1 \%)$ with nausea, 2 patients $(7,2 \%)$ with vomitus, 2 patients $(7,2 \%)$ with hypersensitivity reactions and one patients $(2,7 \%)$ with 
asthenia. However, there was no justification to reduce the chemotherapy doses. There was no treatment related mortality; during the median follow- up of 9,8 months, 34 patients died of cancer progression ant two died of a cerebrovascular event.

\section{DISCUSSION}

Platinum- based regimens have been the mainstay of lung cancer chemotherapy since a meta- analysis in 1995 demonstrated their statistically significant survival benefit over the best supportive care alone for treating advanced NSCLC (10). Those advanced NSCLC patients who exhibit disease progression or local relapse after first- line chemotherapy may be candidates for second- line treatment. Two drug combination regimens have shown increased toxicities without any survival benefits, and the increased toxicity has sometimes led to toxicity- related deaths. Consequently, single- agent chemotherapy has been actively attempted, and this has become the preferred treatment option in a second- line setting (11).

Docetaxel has been studied extensively and has been approved as an effective second- line agent in the treatment of NSCLC. In phase II trials in platinum- treated NSCLC, Docetaxel at doses of $100 \mathrm{mg} / \mathrm{m} 2$ every 3 weeks produced RRranging between $16 \%$ and $31 \%(12,13)$. Shepherd et al. (14) compared second- line Docetaxel with best supportive care, showing survival prolongation using Docetaxel and a 1- year survival rate of $37 \%$, in line with survival rates observed using first- line chemotherapy. A dose of $75 \mathrm{mg} / \mathrm{m} 2$ was recommended, since the dose of $100 \mathrm{mg} / \mathrm{m} 2$ resulted in five deaths. In a phase III randomized study, Fossella et al. (15) compared two doses of Docetaxel (100 and $75 \mathrm{mg} / \mathrm{m} 2)$ administered 3- weekly with a control regimen of Vinorelbine or Ifosfamide, demonstrating RR of $10,8 \%$ and $6,7 \%$ for the two doses of Docetaxel, respectively, compared with a RR of $0,8 \%$ observed with Vinorelbine or Ifosfamide. In addition, a 1- year survival rate of $32 \%$, observed in both Docetaxel arms, was significantly greater than the $10 \%$ survival rate observed in the Vinorelbine or Ifosfamide arm $(\mathrm{P}<0.01)$. With the above amassed knowledge, Docetaxel represent the standard of care for second- line treatment for NSCLC patients.

The results of present study are remarkably similar to those, observed in previously reported trials with Docetaxel as second- line treatment in patients with stage IIIB/ IV NSCLC $(14,15)$. Indeed, OS in these trials was 5,7- 7,0 months, median PFS 2,12- 2,65 months and ORR- 5,8\%- 6,7\%. The current study reported a median OS of 5,6 months, a median PFS of 4,5 months, ORR- $16,6 \%$, with six PR, and tumor control rate achieved- 38,8\%. These observations are promising. Efficacy results in the current study were obtained with an acceptable toxicity profile. The incidence of grade 3 or more neutropenia and febrile neutropenia were $25 \%$ and $11,1 \%$, respectively. Due to hematological toxicity chemotherapy was postponed in 19 cycles. Non- hematological toxicity was mild to moderate.
No treatment related mortality was observed.

In conclusion, our results indicate that Docetaxel treatment in pretreated patients with NSCLC appears promising with of survival rate of 4,5 months, the low hematological and non- hematological toxicity and nonoverlapping toxicity. This treatment merits further evaluation in prospective trials with combination with other chemotherapy agents.

Table 1. Patient characteristics

\begin{tabular}{|l|l|}
\hline Patient characteristics & Number of patients -36 \\
\hline Age (years) & $39-76$ \\
\hline Sex & $28(77,7 \%)$ \\
Males & $8(22,3 \%)$ \\
Females & \\
\hline Dominant site of metastasis & $12(33,3 \%)$ \\
Pleura & $10(27,7 \%)$ \\
Liver & $3(8,3 \%)$ \\
Lung & $7(19,7 \%)$ \\
Bone & $2(5,5 \%)$ \\
Soft tissue & $2(5,5 \%)$ \\
Other & \\
\hline Performance status WHO & $4(11,2 \%)$ \\
0 & $17(47,2 \%)$ \\
1 & $15(41,6 \%)$ \\
2 & \\
\hline Stage & $14(38,8 \%)$ \\
III & $22(61,2 \%)$ \\
IV & \\
\hline Histology & $24(66,7 \%)$ \\
Squamous & $8(22,3 \%)$ \\
Adenocarcinoma & $2(5,5 \%)$ \\
Large- cell & $2(5,5 \%)$ \\
Other & \\
\hline Response to previous first- & $3(8,3 \%)$ \\
linechemotherapy & $3(1,6 \%)$ \\
Complete remission & $9(25,0 \%)$ \\
Partial response & $14(38,9 \%)$ \\
Stable disease & $10(27,7 \%)$ \\
Progressive disease & $12(32,2 \%)$ \\
\hline Co- morbidity & $82,3 \%)$ \\
Hypertension & \\
Diabetes mellitus & \\
Pulmonary thrombembolism & \\
\hline & \\
\hline
\end{tabular}


Table 2. Objective responses

\begin{tabular}{|l|c|c|c|c|c|}
\hline $\begin{array}{l}\text { Patients/ } \\
\text { Response (N) }\end{array}$ & CR & PR & NC & PD & $\begin{array}{c}\text { Tumor control } \\
\text { rate (\%) }\end{array}$ \\
\hline 36 & 0 & 6 & 8 & 17 & $38,8 \%$ \\
\hline
\end{tabular}

Tumor control rate $=\mathrm{CR}+\mathrm{PR}+\mathrm{NC}$

CR, Complete response; PR, Partial response; NC, No change; PD, Progressive disease; ORR; N- Number of patients

Table 3. Adverse drug reactions by symptomshematological, grade 3-4

\begin{tabular}{|l|c|}
\hline Adverse drug reactions & Number of patients \\
\hline Neutropenia & $9(25,0 \%)$ \\
\hline Febrile neutropenia & $4(11,1 \%)$ \\
\hline Anemia & $2(5,5 \%)$ \\
\hline
\end{tabular}

Table 4. Adverse drug reactions- non- hematological, grade 3- 4

\begin{tabular}{|l|c|}
\hline Adverse drug reactions & Number of patients \\
\hline Asthenia & $1(2,7 \%)$ \\
\hline Nausea & $4(11,1 \%)$ \\
\hline Vomitus & $2(7,2 \%)$ \\
\hline Diarrhea & $3(8,3 \%)$ \\
\hline Hypersensitivity reaction & $2(7,2 \%)$ \\
\hline
\end{tabular}

\section{REFERENCES:}

1. Ferlay J, Autier P, Boniol M, Heanue M, Colombet M, Boyle P. Estimates of the cancer incidence and mortality in Europe in 2006. Ann Oncol. 2007 Mar;18(3):581-592. [PubMed] [CrossRef]

2. Jemal A, Siegel R, Ward E, Murrey $\mathrm{T}, \mathrm{Xu}$ J, Smigal C, et al. Cancer statistics, 2006. CA Cancer J Clin. 2006 MarApr;56(2):106-130. [PubMed]

3. Yang P, Allen MS, Aubry MC, Wampflerm JA, Marks RS, Edell ES, et al. Clinical features of 5,628 primary lung cancer patients: experience at Mayo Clinic from 1997 to 2003. Chest. 2005 Jul;128(1):452- 462. [PubMed] [CrossRef]

4. Schiller JH, Harrington D, Belani CP, Langer C, Sandler A, Krook J, et al. Comparison of four chemotherapy regimens for non- small- cell lung cancer. $N$ Engl $J$ Med. 2002 Jan 10;346(2):92-98. [PubMed] [CrossRef]

5. Georgoulias VA. Second- line chemotherapy in relapsing or refractory patients with non- small cell lung cancer. Lung Cancer. 2002 Dec;38 Suppl 3:61-66. [PubMed]

6. Fossella FV, Lee JS, Hong WK. Management strategies for recurrent nonsmall cell lung cancer. Semin Oncol. 1997
Aug;24(4):455- 462. [PubMed]

7. Shepherd FA, Dancey J, Ramlau R, Mattson K, Gralla R, O'Rourke M, et al. Prospective randomized trial of docetaxel versus best supportive care in patients with non- small- cell lung cancer previously treated with platinum- based chemotherapy. J Clin Oncol. 2000 May;18(10):2095- 2103. [PubMed]

8. Miller AB, Hoogstraten B, Staquet M, Winkler A. Reporting results of cancer treatment. Cancer. 1981 Jan 1;47(1):207214. [PubMed]

9. Brimdage MD, Pater JL, Zee B. Assessing the reliability of two toxicity scales: Implications for interpreting toxicity data. J Natl Cancer Inst. 1993 Jul 21;85(14):38- 48. [Pubmed] [CrossRef]

10. Chemotherapy in non-small cell lung cancer: a meta-analysis using updated data on individual patients from 52 randomised clinical trials. Non-small Cell Lung Cancer Collaborative Group. BMJ. 1999 Oct 7;311(7010):899-909. [PubMed] [CrossRef]

11. Bartesi F, Jacot W, Astoul P, Pujol JL. Second line treatment for advanced nonsmall cell lung cancer: a systematic review. Lung cancer. 2006 Feb;51(2):159-172.
[PubMed] [CrossRef]

12. Gandara DR, Vokes E, Green M, Bonomi P, Devore R, Comis R, et al. Activity of docetaxel in platinum-treated non- small- cell lung cancer: Results of a phase II multicenter trial. $J$ Clin Oncol. 2000 Jan;18(1):131-135. [PubMed]

13. Le Chevalier T. Docetaxel: meeting the challenge of non- small- cell lung cancermanagement. Anticancer drugs. 1995 Jul;6 Suppl 4:13-17. [PubMed]

14. Shepferd FA, Dancey J, Ramlau R, Mattson K, Gralla R, O'Rourke M, et al. Prospective randomized trial of docetaxel versus best supportive care in patients with non-small-cell lung cancer previously treated with platinum-based chemotherapy. $J$ Clin Oncol. 2000 May;18(10):2095-2103. [PubMed]

15. Fosella FV, DeVore R, Kerr RN, Crawforf J, Natale RR, Dunphy F. et al. Randomized phase III trial of docetaxel versus vinorelbine or ifosfamide in patients with advanced non- small- cell lung cancer previously treated with platinum-containing chemotherapy regimens. The TAX 320 Non-Small Cell Lung Cancer Study Group, J Clin Oncol. 2000 Jun;18(12):2354- 2362. [PubMed]

\section{Address for correspondence:}

Dr. Deyan Nikolov Davidov,

Department of Chemotherapy, Oncological Center, Medical University;

1, "St. Kliment Ohridsky" Str., 5000 Pleven, Bulgaria,

Phone: +359/64/886 138, Fax: +359/64/831634;

E-mail: dean_davidov@abv.bg; 